Rev. Bras. Saúde Prod. Anim., Salvador, v.17, n.1, p.101-115 jan./mar., 2016 http://www.rbspa.ufba.br

\title{
Medidas in vivo e da carcaça e constituintes não carcaça de ovinos alimentados com diferentes níveis do subproduto agroindustrial da goiaba
}

\author{
Measurements "in vivo" and of carcasses and constituents non-carcasses of sheep fed \\ with different levels of guava agroindustrial by-product
}

\author{
SILVA, Nelson Vieira $\mathrm{da}^{1 *}$; COSTA, Roberto Germano ${ }^{2}$; MEDEIROS, Geovergue \\ Rodrigues de ${ }^{3}$; GONZAGA NETO, Severino ${ }^{2}$; CÉZAR, Marcilio Fontes ${ }^{4}$; \\ CAVALCANTI, Maria Caroline Albuquerque ${ }^{2}$
}

\footnotetext{
${ }^{1}$ Instituto Federal de Alagoas, Departamento de Agropecuária, Santana do Ipanema, Alagoas, Brasil.

${ }^{2}$ Universidade Federal da Paraíba, Centro de Ciências Agrárias, Departamento de Zootecnia, Areia, Paraíba, Brasil.

${ }^{3}$ Instituto Nacional do Semiárido, Campina Grande, Paraíba, Brasil.

${ }^{4}$ Universidade Federal de Campina Grande, Centro de Saúde e Tecnologia Rural, Departamento de Ciência Animal, Patos, Paraíba, Brasil.

*Endereço para correspondência: zoonelson@hotmail.com
}

\section{RESUMO}

O objetivo com este estudo foi avaliar a biometria, morfometria e os órgãos não-componentes da carcaça de ovinos Santa Inês, em confinamento, alimentadas com níveis crescentes $(0 ; 20 ; 40$ e $60 \%$ na matéria seca) de subproduto agroindustrial da goiaba como um substituto para o milho. Quarenta ovinos Santa Inês, machos (não castrados), com média de $17,41 \pm 1,27 \mathrm{~kg}$ de peso corporal (PC) e 120 dias de idade no início do estudo, foram utilizados neste experimento. Os animais foram abatidos aos $32 \mathrm{~kg}$ ou 105 dias de confinamento. Foi utilizado o delineamento inteiramente casualizado, com dez repetições por tratamento. Os animais submetidos a dietas com $60 \%$ de substituição apresentaram menor comprimento corporal $(63,20 \mathrm{~cm})$, menor altura de cernelha $(67,30 \mathrm{~cm})$ e de garupa $(69,50 \mathrm{~cm})$, baixo escore de condição corporal (2,40 pts), carcaças de conformação inferior (2,25 pts), menor perímetro do tórax $(65,10 \mathrm{~cm})$ e baixos rendimentos de órgãos como coração $(0,52 \%)$, baço $(0,15 \%)$, rins $(0,25 \%)$ e pulmão $(0,89 \%)$. O milho pode ser substituído pelo subproduto da goiaba em níveis de até $40 \%$, sendo relevante a obtenção de animais com características corporais desejáveis para produção de carne e com rendimento de órgãos não constituintes da carcaça satisfatórios ao mercado.

Palavras-chave: buchada, biometria, índices zootécnicos, morfometria, Psidium guajava L.

\section{SUMMARY}

The objective of this study was to evaluate the biometrics, morphometry and the organs do non-constituents of the carcass of feedlot Santa Inês sheep fed with increasing levels $(0 ; 20 ; 40$ and $60 \%$ dry matter basis) of guava agroindustrial by-products as a replacement for corn. Forty male (noncastrated) Santa Inês sheep, averaging $17.41 \pm 1.27 \mathrm{~kg}$ body weight (BW) and 120 days of age at the beginning of the study, were used in this trial. The animals were slaughtered at $32 \mathrm{~kg}$ or 105 days of confinement. A completely randomized design with ten replicates per treatment was used. The animals submitted to diets with $60 \%$ substitution showed lower body length $(63.20 \mathrm{~cm})$, lower withers height $(67.30 \mathrm{~cm})$ and hip $(69.50 \mathrm{~cm})$, low body condition score $(2.40$ pts), lower carcass of conformation (2.25 pts), lower chest perimeter $(65.10 \mathrm{~cm})$ and low yields of organs such as heart $(0.52 \%)$, spleen $(0.15 \%)$, kidneys $(0,25 \%)$ and lung $(0.89 \%)$. Corn can be replaced by guava agroindustrial by-product at levels up to $40 \%$, being relevant to obtain animals with body characteristics desirable for meat production and yield of organs non-constituents of carcass satisfactory to the market.

Keywords: buchada, biometric, morfometrics, Psidium guajava L., zootechnical índice 
Rev. Bras. Saúde Prod. Anim., Salvador, v.17, n.1, p.101-115 jan./mar., 2016 http://www.rbspa.ufba.br

\section{INTRODUÇÃO}

O aumento da fruticultura na região Nordeste do Brasil, aliado ao uso de modernas tecnologias de irrigação, tem contribuído para instalação de agroindústrias e, conseqüentemente, para geração de um grande volume de resíduos com potencial uso na ração de ruminantes (LOUSADA JUNIOR et al., 2006). Todavia, o crescente consumo de carne ovina no Brasil tem levado o setor a buscar alternativas alimentares para suprir a demanda, sobretudo na região Nordeste, onde o milho é importado de outras regiões, encarecendo os custos de produção devido ao alto preço do frete. Portanto, a utilização de subprodutos agroindustriais surge como tecnologia inovadora para produção de carne em sistemas eficientes e sustentáveis de produção (MURTA et al., 2011), sobretudo por apresentar características nutricionais próximas ao milho como CNF de $12,70 \%$ e PB de $8,47 \%$ (LOUSADA JUNIOR et al., 2006).

Os subprodutos derivados do processamento da goiaba (Psidium guajava L.), composto por casca, caroço e parte da polpa, podem ser aproveitados na dieta de ruminantes após o processo de desidratação (PEREIRA et al., 2008), por apresentar boa palatabilidade (LOUSADA JUNIOR et al., 2006). Porém, apresenta limitações devido à baixa digestibilidade de nutrientes (AZÊVEDO et al., 2011). Assim, para utilização é necessário estudos envolvendo a resposta animal.

Estudos sobre o desempenho de ovinos têm se restringido a discutir as características de produção, como ganho de peso e qualidade da carcaça, considerando-se, poucas vezes, as partes não integrantes da carcaça. Os constituintes têm importância econômica, podendo agregar valor à produção ovina (SANTOS et al., 2008) e tendem a variar com as dietas, influenciando o rendimento de carcaça e o ganho de peso (CLEMENTINO et al., 2007), estando o seu tamanho associados às diferenças nas exigências de mantença (SMITH \& BALDWIN, 1973). É importante, também, a busca do padrão ideal do animal para produção de carne, pois a biometria reflete a aptidão produtiva e o estado nutricional. Todavia, a quantificação dos órgãos não constituintes da carcaça e a mensuração das medidas corporais podem reduzir as perdas econômicas e proporcionar a correta valorização dos animais para produção de carne.

Face às considerações, objetivou-se estudar a influencia de dietas contendo diferentes níveis de substituição do milho pelo subproduto da goiaba sobre as medidas corporais, órgãos não constituintes da carcaça e suas correlações em ovinos da raça Santa Inês.

\section{MATERIAL E MÉTODOS}

O experimento foi realizado no Instituto Federal de Educação, Ciência e Tecnologia de Pernambuco - IFPE, Campus Belo Jardim, em Belo Jardim PE. Foram utilizados 40 cordeiros, machos não castrados, da raça Santa Inês, com idade média de 120 dias e peso inicial (PI) de 17,41 $\pm 1,27 \mathrm{~kg}$. Os animais foram inicialmente vermifugados com aplicação subcutânea de ivermectina a $1 \%$, em seguida distribuídos em baias individuais com área de $1,8 \mathrm{~m}^{2} \mathrm{com}$ acesso livre a comedouros e bebedouros. As rações tinham como ingredientes subproduto da goiaba, feno de capim tifiton, milho moído, farelo de soja, óleo vegetal e uréia (Tabela 1). Os tratamentos dietéticos consistiram em níveis parciais de substituição do milho $(0 ; 20 ; 40$ e $60 \%$ ) pelo subproduto agroindustrial da goiaba (Tabela 2). 
Rev. Bras. Saúde Prod. Anim., Salvador, v.17, n.1, p.101-115 jan./mar., 2016 http://www.rbspa.ufba.br ISSN 15199940 http://dx.doi.org/10.1590/S1519-99402016000100010

Tabela 1. Composição bromatológica dos ingredientes da ração em \% da MS

\begin{tabular}{lccccccccc}
\hline Ingrediente & MS & MO & MM & PB & EE & FDN $^{1}$ & FDA $^{1}$ & NDT $^{1}$ & Lignina $^{1}$ \\
\hline Subproduto da goiaba & 90,35 & 97,47 & 2,53 & 9,44 & 10,72 & 75,30 & 58,18 & 34,57 & 19,70 \\
Feno de capim Tifton & 80,73 & 92,61 & 7,39 & 7,98 & 1,74 & 78,64 & 39,04 & 55,74 & 5,50 \\
Milho moído & 87,51 & 96,99 & 3,01 & 8,56 & 5,71 & 13,52 & 3,83 & 85,94 & 1,19 \\
Farelo de soja & 87,79 & 93,77 & 6,23 & 47,07 & 2,02 & 15,54 & 9,60 & 80,68 & 1,52 \\
'Óleo vegetal & 100 & - & - & - & 99,9 & - & - & 184,00 & - \\
${ }^{1}$ Uréia & 100 & - & - & 281 & - & - & - & - & - \\
\hline & IV Valores da tabela de composicão de Valadares Filho et al. (2006)
\end{tabular}

Tabela 2. Composição percentual e bromatológica das dietas experimentais

\begin{tabular}{|c|c|c|c|c|}
\hline \multirow{2}{*}{$\begin{array}{l}\text { Composição percentual (\% } \\
\text { MS) }\end{array}$} & \multicolumn{4}{|c|}{ Níveis de Substituição (\%) } \\
\hline & 0 & 20 & 40 & 60 \\
\hline Subproduto da goiaba & 0,0 & 8,2 & 16,4 & 24,6 \\
\hline Feno de capim tifton & 30,0 & 30,0 & 30,0 & 30,0 \\
\hline Grão de milho moído & 41,0 & 32,8 & 24,6 & 16,4 \\
\hline Farelo de soja & 22,0 & 22,0 & 22,0 & 22,0 \\
\hline Uréia & 0,5 & 0,5 & 0,5 & 0,5 \\
\hline Suplemento mineral & 1,5 & 1,5 & 1,5 & 1,5 \\
\hline Óleo vegetal & 5,0 & 5,0 & 5,0 & 5,0 \\
\hline \multicolumn{5}{|c|}{ Composição Bromatológica (\% MS) } \\
\hline Matéria seca & 84,39 & 84,62 & 84,85 & 85,09 \\
\hline Proteína bruta & 17,67 & 17,74 & 17,81 & 17,88 \\
\hline Extrato etéreo & 8,29 & 8,69 & 9,10 & 9,42 \\
\hline Material mineral & 4,81 & 4,76 & 4,73 & 4,69 \\
\hline Matéria orgânica & 88,16 & 88,20 & 88,23 & 88,27 \\
\hline Fibra em detergente neutro & 32,55 & 37,61 & 42,68 & 47,75 \\
\hline Fibra em detergente ácido & 15,39 & 19,85 & 24,30 & 28,76 \\
\hline Carboidratos não fibrosos & 36,68 & 31,20 & 25,68 & 20,26 \\
\hline Taninos totais & 0,00 & 0,50 & 2,40 & 4,80 \\
\hline Lignina & 2,47 & 3,99 & 5,50 & 7,02 \\
\hline Nutrientes digestíveis totais & 78,90 & 74,70 & 70,50 & 66,30 \\
\hline Energia digestível $^{1}$ & 3,47 & 3,29 & 3,10 & 2,92 \\
\hline Energia metabolizável $^{1}$ & 2,84 & 2,69 & 2,54 & 2,39 \\
\hline
\end{tabular}

${ }^{1}(\mathrm{Mcal} / \mathrm{kg} \mathrm{MS})$.

O subproduto da extração do suco da goiaba, composto por casca, sementes e polpa, foi submetido à pré-secagem ao sol por aproximadamente 24 horas e armazenadas em sacos de nylon para posterior utilização. As rações foram formuladas objetivando ganhos de $250 \mathrm{~g} /$ dia, numa relação volumoso:concentrado de 30:70, conforme as recomendações do NRC (2007). O período de adaptação as dietas e as instalações foram de 15 dias e as pesagens realizadas semanalmente. As dietas foram ofertadas ad libitum nos horários de $7 \mathrm{~h} 30 \mathrm{mim}$ e $16 \mathrm{~h} 30 \mathrm{mim}$, na forma de dieta completa, estabelecendose $10 \%$ de sobras.

As medidas corporais in vivo foram obtidas segundo a metodologia descrita por Santana et al. (2001), onde: Peso vivo ao abate - obtido por pesagem do animal $(\mathrm{kg})$ em balança frigorífica antes do abate; Altura de cernelha - distância vertical entre $\mathrm{o}$ ponto mais alto da 
Rev. Bras. Saúde Prod. Anim., Salvador, v.17, n.1, p.101-115 jan./mar., 2016 http://www.rbspa.ufba.br ISSN 15199940

cernelha e o solo, com o animal mantido em posição correta de aprumos; Altura de garupa - distância vertical entre o ponto mais alto da garupa e o solo, com o animal mantido em posição correta de aprumos; Comprimento corporal - distância entre a base da cauda e a base do pescoço; Escore corporal - medida avaliada subjetivamente para verificar o estado de engorduramento do animal através de apalpação na região lombar e do externo, atribuindo notas que variam de um (magro) a cinco (muito gordo); Perímetro torácico - mensuração obtida na parte posterior das espátulas junto às axilas; Comprimento da perna distância entre o períneo e o bordo anterior da superfície articular tarso metatarsiana; Largura do peito distancia máxima entre as pontas das duas espátulas, tomada horizontalmente e frontalmente ao animal por meio de uma fita métrica graduada e compasso. $\mathrm{O}$ índice de compacidade corporal (CC1) foi tomado seguindo a metodologia de Costa Júnior et al. (2006), onde: Índice de compacidade corporal (CC1) - índice zootécnico obtido através da relação entre o peso vivo $(\mathrm{kg})$ e o comprimento do corpo (cm) do animal.

Os parâmetros para abate dos animais foram o peso corporal de $32 \mathrm{~kg}$ ou 105 dias de confinamento, período máximo preestabelecido para duração da terminação. Portanto, os animais que foram atingindo $32,0 \mathrm{~kg}$ de peso corporal foram abatidos e, aos 105 dias de confinamento, o restante foi abatido, independente do peso. Antes do abate os animais foram pesados para obtenção do peso vivo final (PVF) e submetidos a jejum de sólidos e dieta hídrica por aproximadamente 18 horas (BRASIL, 1952). Decorrido o período do jejum, os animais foram novamente pesados para obtenção do peso vivo ao abate (PVA).
O abate foi procedido com atordoamento por concussão cerebral, seguida de sangria através de incisão na veia jugular e artéria carótida. Em seguida foram esfolados e eviscerados, obtendo-se a pesagem do trato gastrointestinal (TGI) composto por intestinos grosso e delgado, e estômagos que corresponde ao peso do rumem-reticulo, omaso e abomaso. Os órgãos não-constituintes da carcaça, como pele, cabeça, patas, sangue, língua, baço, fígado, coração e rins, e gorduras internas renal, omental e mesentérica foram quantificados. As carcaças foram lavadas, pesadas e penduradas pelos tendões calcâneo comum em ganchos apropriados $\mathrm{e}$ distanciadas uma da outra por $17 \mathrm{~cm}$, e submetidas à refrigeração em câmara fria a $4^{\circ} \mathrm{C}$ por 24 horas.

As medidas morfométricas foram tomadas segundo a metodologia descrita por Cezar \& Souza (2007), onde: Conformação da carcaça avaliação visual da carcaça, levando-se em conta a espessura de seus planos musculares e adiposos em relação ao tamanho do esqueleto que os suportam, atribuindo notas de 1 a 5 pontos; Comprimento da carcaça - distância entre a base do pescoço e a base da cauda; Comprimento interno da carcaça - distância máxima entre o bordo anterior da síntese ísquio-pubiana e o bordo anterior da primeira costela em seu ponto médio; Comprimento da perna - distância entre o períneo, em sua borda mais distal, e o bordo interior da superfície articular tarso-metatarsiana, pela face interna da perna; Perímetro da coxa - perímetro tomado em torno da coxa, tendo como referência a passagem da fita métrica sobre os músculos que circundam o osso fêmur; Perímetro da garupa - perímetro tomado em torno da garupa, tendo como referência a passagem da fita métrica sobre os dois 
Rev. Bras. Saúde Prod. Anim., Salvador, v.17, n.1, p.101-115 jan./mar., 2016 http://www.rbspa.ufba.br ISSN 15199940

trocânteres de ambos os fêmures; Largura da garupa - distância máxima entre os dois trocânteres de ambos os fêmures; Profundidade do tórax consiste na distancia máxima entre o esterno e o dorso da carcaça ao nível da sexta vértebra torácica; Perímetro do tórax - perímetro tomado em torno do tórax, tendo como referência a passagem da fita métrica sobre a ponta do externo e as vértebras dorsais; Indice de compacidade da perna - relação entre a largura de garupa e o comprimento da perna $(\mathrm{ICP}=\mathrm{LG} / \mathrm{CP}) \mathrm{e}$ Índice de compacidade da carcaça peso da carcaça fria, dividido pelo comprimento interno da carcaça $(\mathrm{ICC}=$ $\mathrm{PCF} / \mathrm{CIC})$.

Utilizou-se o delineamento inteiramente ao acaso, com quatro tratamentos e dez repetições. As equações de regressão múltipla foram realizadas para estimativa do peso vivo ao abate (PVA), peso de carcaça quente (PCQ), peso de carcaça fria (PCF), índice de compacidade da carcaça (ICC), índice de compacidade da perna (ICP), rendimento de constituintes não-carcaça comestíveis (RCC) e conformação da carcaça (CC), considerando o modelo constituído pelas medidas e pelas relações morfométricas selecionadas. Os dados foram analisados através dos procedimentos GLM (modelo linear geral), REG (regressão) e CORR (correlação) do SAS $^{\circledR}$. Foram testados os efeitos de grau linear, quadrático e cúbico. Os critérios utilizados na escolha das equações foram $o$ comportamento biológico, o coeficiente de determinação $\left(r^{2}\right)$ e a significância, para os parâmetros de regressão, obtida pelo teste "t - Student", considerando significância de $1 \%$ a $5 \%$ de probabilidade. As equações de regressão foram ajustadas usando o PROC REG do SAS.

\section{RESULTADOS E DISCUSSÃO}

Observou-se que a cada $1 \%$ de substituição do milho pelo subproduto da goiaba na dieta os animais deixaram de ganhar $0,039 \mathrm{~kg} ; 0,066 \mathrm{~cm} ; 0,051 \mathrm{~cm}$; $0,051 \mathrm{~cm}$ e 0,009 pontos, nas características de peso vivo ao abate, comprimento corporal, altura de cernelha, altura de garupa e escore corporal, respectivamente (Tabela 3 ). O peso vivo ao abate dos cordeiros decresceu linearmente à medida que se elevou a percentagem de substituição $(\mathrm{p}<0,018)$, indicando que a cada unidade percentual acrescida, os animais perderam em média $39 \mathrm{~g}$, o que pode esta relacionada à redução da energia da dieta e aos efeitos antinutricionais dos taninos dietéticos que aumentaram à medida que se elevou os níveis de substituição, conforme observado na Tabela 2.

O comportamento semelhante observado entre as medidas corporais in vivo e o peso vivo ao abate demonstra que as equações geradas servem para estimar o melhor peso do animal para abate. Os resultados da presente pesquisa corroboram a afirmativa de Pinheiro et al. (2009), de que a biometria permite predizer, de maneira prática e econômica, o estado nutricional do animal e as características da carcaça. É importante ressaltar que o peso do animal, quando tomado como medida isolada, pode superestimar ou subestimar a composição real dos tecidos na carcaça a depender do tipo da dieta utilizada.

Observou-se influencia das dietas sobre as medidas corporais $(p<0,001)$, exceto perímetro torácico, largura de garupa e compacidade corporal. $\mathrm{O}$ teor energético decresceu conforme a inclusão do subproduto da goiaba nas dietas, o que pode explicar o fenômeno. 
Rev. Bras. Saúde Prod. Anim., Salvador, v.17, n.1, p.101-115 jan./mar., 2016 http://www.rbspa.ufba.br ISSN 15199940

A ausência de efeito de regressão na medida de perímetro torácico $(\mathrm{p}>0,001)$ não era esperada, visto que essa medida é a que mais se correlaciona com o peso vivo ao abate, que por sua vez, foi influenciada pelos níveis de substituição. Os resultados dessa pesquisa diferem daqueles apresentados por Castro et al. (2012), que estudando a biometria de cordeiros Santa Inês, observaram que o perímetro torácico é, dentre as medidas biométricas, a que melhor se correlaciona com o peso dos animais.

Tabela 3. Biometria e índice de compacidade corporal de cordeiros da raça Santa Inês, submetidos a dietas com níveis de substituição do milho pelo subproduto da goiaba

\begin{tabular}{|c|c|c|c|c|c|c|c|}
\hline \multirow{2}{*}{ Características } & \multicolumn{4}{|c|}{ Níveis de Substituição (\%) } & \multirow{2}{*}{ CV $(\%)$} & \multirow{2}{*}{$\begin{array}{l}\text { Efeito de } \\
\text { regressão }\end{array}$} & \multirow{2}{*}{$\mathrm{P}$} \\
\hline & 0 & 20 & 40 & 60 & & & \\
\hline${ }^{1}$ Peso vivo ao abate $(\mathrm{kg})$ & 30,85 & 30,14 & 29,83 & 28,32 & 3,56 & Linear & $<0,001$ \\
\hline${ }^{2}$ Ganho de peso diário, $\mathrm{kg}$ & 0,26 & 0,22 & 0,22 & 0,12 & 15,69 & Linear & $<0,001$ \\
\hline${ }^{3}$ Comprimento corporal $(\mathrm{cm})$ & 66,90 & 67,90 & 65,80 & 63,20 & 5,71 & Linear & 0,018 \\
\hline Perímetro torácico $(\mathrm{cm})$ & 72,50 & 71,50 & 72,30 & 70,90 & 3,04 & NS & 0,306 \\
\hline${ }^{4}$ Altura de cernelha $(\mathrm{cm})$ & 70,70 & 69,80 & 69,70 & 67,30 & 3,20 & Linear & 0,002 \\
\hline${ }^{5}$ Altura de garupa $(\mathrm{cm})$ & 72,80 & 72,30 & 72,00 & 69,50 & 3,07 & Linear & 0,002 \\
\hline Largura de garupa $(\mathrm{cm})$ & 23,30 & 21,70 & 21,50 & 20,10 & 13,19 & NS & 0,116 \\
\hline${ }^{6}$ Escore $(1-5$ pts $)$ & 3,05 & 2,70 & 2,65 & 2,40 & 12,75 & Linear & $<0,001$ \\
\hline Compacidade corp. $(\mathrm{kg} / \mathrm{cm})$ & 0,49 & 0,47 & 0,49 & 0,47 & 6,07 & NS & 0,661 \\
\hline
\end{tabular}

${ }^{\mathrm{T}} \mathrm{Y}=30,97-0,039 \mathrm{x}\left(\mathrm{R}^{2}=0,91\right) ;{ }^{2} \mathrm{Y}=0,26-0,004 \mathrm{x}(\mathrm{R} 2=0,99) ;{ }^{3} \mathrm{Y}=67,93-0,066 \mathrm{x}\left(\mathrm{R}^{2}=0,70\right) ;{ }^{4} \mathrm{Y}=70,92-$ $0,051 \mathrm{x}\left(\mathrm{R}^{2}=0,83\right) ;{ }^{5} \mathrm{Y}=73,18-0,051 \mathrm{x}\left(\mathrm{R}^{2}=0,80\right) ;{ }^{6} \mathrm{Y}=3,01-0,009 \mathrm{x}\left(\mathrm{R}^{2}=0,84\right) ; \mathrm{NS}=$ não significativo; $\mathrm{P}$

= significância.

Os animais alimentados com menores níveis de substituição apresentaram melhor desenvolvimento, refletido pelo maior comprimento corporal, maior altura de cernelha, altura de garupa e melhores escores de condição corporal. $\mathrm{O}$ resultado pode está relacionado à redução de 15,96\% nos teores de NDT entre o menor e o maior nível de substituição. O comprimento corporal médio dos cordeiros foi de $65,95 \mathrm{~cm}$, superior aos $63,7 \mathrm{~cm}$ observados por Sousa et al. (2009) ao estudarem as medidas in vivo de animais Santa Inês abatidos com peso médio corporal de 30 kg. Animais compridos, nem sempre são os mais bem conformados, uma vez que a conformação é avaliada pela relação entre os perfis musculares, sendo preconizadas carcaças curtas, largas e compactas, situação observada apenas nos animais alimentados com níveis de substituição de até $40 \%$.

Houve decréscimo linear $(\mathrm{P}=0,0023)$ com a substituição do milho pelo subproduto da goiaba na altura de cernelha e garupa, observando-se coeficientes de determinação de $\mathrm{r}^{2}=$

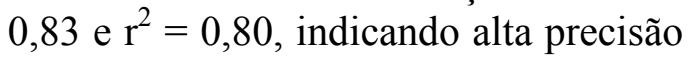
da equação, respectivamente. Houve efeito linear decrescente sobre o escore corporal $(\mathrm{P}<0,001)$ dos cordeiros, o que é reflexo do menor aporte nutricional dos animais que receberam dietas com maiores níveis de substituição do milho pelo subproduto da goiaba. O resultado pode estar relacionado ao decréscimo no consumo de MS com a introdução do subproduto da goiaba na dieta, 1,35; 1,$29 ; 1,25$ e $1,18 \mathrm{~kg} /$ dia para os níveis de 
Rev. Bras. Saúde Prod. Anim., Salvador, v.17, n.1, p.101-115 jan./mar., 2016 http://www.rbspa.ufba.br ISSN 15199940

$0,20,40$ e $60 \%$, respectivamente. Os resultados refletem, também, o decréscimo na concentração de energia e a alta ingestão de taninos condensados nas dietas com níveis mais altos de substituição. $\mathrm{O}$ aumento nos teores de taninos condensados reduz a hidrolise dos nutrientes não sendo absorvidos pelo trato gastrointestinal (LUCIANO et al., 2009). Os cordeiros foram classificados na condição corporal intermediária, com escore variando de 2,40 a 3,05 .

Houve efeito linear decrescente sobre a medida de conformação da carcaça $(\mathrm{P}<0,001)$, comprimento da carcaça $(\mathrm{P}=0,0399)$, perímetro da coxa $(\mathrm{P}<0,001)$, perímetro do tórax $(\mathrm{P}=0,0028)$ e índice de compacidade da carcaça $(\mathrm{P}<0,001)$ em função dos níveis de substituição (Tabela 4). Os valores decrescentes para o índice de compacidade da carcaça indicam redução na deposição de tecido por unidade de comprimento, em torno de $0,0007 \mathrm{~kg} / \mathrm{cm}$ a cada unidade percentual de substituição do milho pelo subproduto da goiaba na dieta, refletindo o baixo peso dos animais quando o subproduto foi adicionado. De acordo com Yáñez et al. (2004), o índice de compacidade da carcaça estima objetivamente a conformação e pode ser utilizada para avaliar a produção de carne de animais com peso vivo semelhante. Contudo, infere-se que a conformação da carcaça é afetada negativamente quando o subproduto da goiaba é adicionado às dietas.

Tabela 4. Morfometria da carcaça de cordeiros da raça Santa Inês em função dos níveis de substituição do milho pelo subproduto agroindustrial da goiaba na dieta

\begin{tabular}{|c|c|c|c|c|c|c|c|}
\hline \multirow{2}{*}{ Características } & \multicolumn{4}{|c|}{ Níveis de Substituição (\%) } & \multirow{2}{*}{ CV $(\%)$} & \multirow{2}{*}{$\begin{array}{l}\text { Efeito de } \\
\text { regressão }\end{array}$} & \multirow{2}{*}{$\mathrm{P}$} \\
\hline & 0 & 20 & 40 & 60 & & & \\
\hline${ }^{1}$ Conformação (1-5 pts) & 2,80 & 2,70 & 2,60 & 2,25 & 11,56 & Linear & $<0,001$ \\
\hline${ }^{2}$ Comp. da carcaça $(\mathrm{cm})$ & 64,40 & 66,00 & 63,90 & 62,30 & 4,34 & Linear & 0,039 \\
\hline Comp. int. da carcaça (cm) & 55,40 & 55,10 & 55,10 & 51,60 & 8,36 & NS & 0,084 \\
\hline Comp. da perna $(\mathrm{cm})$ & 40,00 & 35,80 & 34,80 & 35,40 & 15,14 & NS & 0,066 \\
\hline${ }^{3}$ Perímetro da coxa $(\mathrm{cm})$ & 35,60 & 32,10 & 32,90 & 30,70 & 8,34 & Linear & $<0,001$ \\
\hline Perímetro da garupa $(\mathrm{cm})$ & 55,10 & 55,70 & 56,30 & 55,80 & 4,25 & NS & 0,560 \\
\hline Largura da garupa $(\mathrm{cm})$ & 20,70 & 19,40 & 20,15 & 19,30 & 12,69 & NS & 0,313 \\
\hline Profundidade do Tórax $(\mathrm{cm})$ & 27,80 & 27,70 & 27,30 & 27,40 & 7,16 & NS & 0,581 \\
\hline${ }^{4}$ Perímetro do tórax $(\mathrm{cm})$ & 68,10 & 66,70 & 67,00 & 65,10 & 2,86 & Linear & 0,002 \\
\hline $\mathrm{ICP}(\mathrm{kg} / \mathrm{cm})$ & 0,53 & 0,54 & 0,58 & 0,54 & 15,52 & NS & 0,536 \\
\hline${ }^{5} \mathrm{ICC}(\mathrm{kg} / \mathrm{cm})$ & 0,27 & 0,25 & 0,24 & 0,22 & 9,05 & Linear & $<0,001$ \\
\hline
\end{tabular}

O fenômeno é explicado pela redução nos teores e consumo de NDT, pelo aumento nos teores de lignina, bem como pela influencia dos taninos dietéticos, que conforme observado na Tabela 2 aumentou à medida que o subproduto foi adicionado. Segundo Min et al. (2003), os taninos podem reduzir a degradação ruminal da proteína e aumentar o fluxo duodenal da proteínas, quando fornecido doses moderadas de 20 a $45 \mathrm{~g} / \mathrm{kg}$ de MS. O 
Rev. Bras. Saúde Prod. Anim., Salvador, v.17, n.1, p.101-115 jan./mar., 2016 http://www.rbspa.ufba.br ISSN 15199940 http://dx.doi.org/10.1590/S1519-99402016000100010

subproduto da goiaba, conforme Azevedo et al. (2011), apresenta limitações para uso em dietas para ruminantes por apresentar baixa disponibilidade de nutrientes, afetando diretamente as medidas da carcaça. Provavelmente, o resultado indica que o maior nível energético proporcionou maior deposição de tecidos. Os animais apresentaram rendimento de órgãos não constituintes da carcaça, comestíveis ou não, de 38,35\%, 35,9\%, 34,62\% e $33,11 \%$ para os níveis de substituição de $0 ; 20 ; 40$ e $60 \%$, respectivamente, desconsiderando o peso do conteúdo do trato gastrointestinal (Tabela 5). O sangue, o TGI e a pele, foram os órgãos que apresentaram maiores rendimentos em relação ao peso vivo ao abate, com médias de 3,88; 7,21 e 7,25\%. A percentagem média de sangue em relação ao peso vivo ao abate $(3,88 \%)$, encontra-se dentro do preconizado na literatura, entre 3 e $4 \%$ para ovinos (MORENO et al., 2011).

Tabela 5. Rendimentos dos constituintes não carcaça comestíveis, subprodutos não comestíveis e gordura interna em relação ao peso vivo ao abate de cordeiros Santa Inês em função dos níveis de substituição do milho pelo subproduto agroindustrial da goiaba na dieta

\begin{tabular}{|c|c|c|c|c|c|c|c|}
\hline \multirow{2}{*}{ Características } & \multicolumn{4}{|c|}{ Níveis de Substituição (\%) } & \multirow{2}{*}{ CV $(\%)$} & \multirow{2}{*}{$\begin{array}{l}\text { Efeito de } \\
\text { regressão }\end{array}$} & \multirow{2}{*}{$\mathrm{P}$} \\
\hline & 0 & 20 & 40 & 60 & & & \\
\hline \multicolumn{8}{|c|}{ Constituintes não-carcaça comestíveis } \\
\hline Cabeça (\%) & 3,95 & 3,94 & 4,16 & 4,21 & 10,38 & NS & 0,106 \\
\hline Língua (\%) & 0,30 & 0,28 & 0,31 & 0,27 & 12,26 & NS & 0,595 \\
\hline${ }^{1}$ Fígado $(\%)$ & 1,98 & 1,73 & 1,65 & 1,25 & 15,03 & Linear & $<0,001$ \\
\hline${ }^{2}$ Coração $(\%)$ & 0,69 & 0,67 & 0,61 & 0,52 & 17,82 & Linear & $<0,001$ \\
\hline${ }^{3}$ Baço $(\%)$ & 0,23 & 0,22 & 0,20 & 0,15 & 18,26 & Linear & $<0,001$ \\
\hline Sangue $(\%)$ & 4,17 & 3,94 & 3,72 & 3,70 & 16,94 & NS & 0,101 \\
\hline${ }^{4} \operatorname{Rins}(\%)$ & 0,33 & 0,30 & 0,30 & 0,25 & 12,37 & Linear & $<0,001$ \\
\hline${ }^{5}$ Pulmão (\%) & 1,24 & 1,26 & 1,08 & 0,89 & 13,56 & Linear & $<0,001$ \\
\hline Esôfago (\%) & 0,39 & 0,19 & 0,24 & 0,21 & 99,64 & NS & 0,184 \\
\hline Traquéia (\%) & 0,68 & 0,77 & 0,64 & 0,67 & 27,53 & NS & 0,541 \\
\hline TGI $(\%)$ & 7,66 & 7,23 & 7,17 & 6,77 & 10,95 & NS & 0,111 \\
\hline \multicolumn{8}{|c|}{ Subprodutos não comestíveis } \\
\hline Patas (\%) & 2,28 & 2,32 & 2,31 & 2,19 & 9,37 & NS & 0,613 \\
\hline Pele $(\%)$ & 7,74 & 7,31 & 7,10 & 6,86 & 10,88 & NS & 0,100 \\
\hline Pênis (\%) & 0,02 & 0,02 & 0,01 & 0,01 & 17,24 & NS & 0,061 \\
\hline Testículos (\%) & 0,98 & 0,92 & 1,03 & 1,00 & 21,25 & NS & 0,569 \\
\hline Vesícula biliar (\%) & 0,13 & 0,10 & 0,09 & 0,08 & 50,60 & NS & 0,186 \\
\hline Bexiga $(\%)$ & 0,28 & 0,32 & 0,29 & 0,24 & 38,40 & NS & 0,657 \\
\hline \multicolumn{8}{|c|}{ Gordura interna } \\
\hline Gord. renal (\%) & 1,40 & 1,14 & 1,03 & 1,06 & 35,71 & NS & 0,063 \\
\hline${ }^{6}$ Gord. omental (\%) & 1,76 & 1,30 & 1,03 & 0,86 & 26,09 & Linear & $<0,001$ \\
\hline Gord.mesentérica (\%) & 2,14 & 1,94 & 1,65 & 1,92 & 24,44 & NS & 0,237 \\
\hline${ }^{7}$ Gordura interna total $(\%)$ & 5,30 & 4,39 & 3,73 & 3,84 & 18,03 & Linear & $<0,001$ \\
\hline
\end{tabular}


O rendimento dos órgãos fígado, coração, baço, rins e pulmão foram influenciados pelos níveis de substituição do milho pelo subproduto da goiaba na dieta $(\mathrm{P}<0,001)$, apresentando percentagens médias de 1,$65 ; \quad 0,62 ; 0,20 ; \quad 0,29$ e $1,11 \%$, respectivamente, em relação ao peso vivo de abate. Segundo Alves et al. (2003), os rendimentos de órgãos vitais, como aparelho respiratório, cérebro e coração, não são influenciados pela composição da dieta, já que esses órgãos têm prioridade na utilização dos nutrientes, mantendo sua integridade independentemente do estado nutricional dos animais.

Com relação aos órgãos ligados à digestão e ao metabolismo dos alimentos, Moreno et al. (2011) afirmam que o tipo de alimentação tem maior influência sobre as proporções dos órgãos. $\mathrm{Da}$ mesma forma, Almeida et al. (2011) afirmam que tecidos muito ativos metabolicamente, a exemplo do fígado e intestino, são mais afetados pela dieta, conseqüentemente, são fortemente influenciados pelo ganho de peso dos animais.

Portanto, os rendimentos dos órgãos podem ser explicados pelo baixo aporte de nutrientes nos animais alimentados com dietas contendo níveis do subproduto da goiaba.

Foi observado decréscimo linear $(\mathrm{P}<0,001)$ no percentual de gordura omental à medida que se elevou os níveis de substituição do milho pelo subproduto da goiaba. Também se observou efeito de regressão sobre a gordura interna total $(\mathrm{P}<0,001)$, com percentuais de 5,$30 ; 4,38 ; 3,71$ e $3,84 \%$, nos níveis de $0 ; 20 ; 40$ e $60 \%$ de substituição, respectivamente. Elevados níveis de energia na dieta favorece maior deposição de gordura, tanto na forma de gordura subcutânea como na cavidade abdominal. Além disso, é sabido que à medida que a idade avança, ocorre crescimento mais intenso dos tecidos muscular e adiposo. Porém, elevada deposição de gordura não é desejável porque, além de aumentar os custos de produção, deprecia as carcaças e gera maiores quantidades de gorduras internas que não são aproveitadas para consumo humano (CAMILO et al., 2012). A gordura interna apresenta função de proteção dos órgãos internos do corpo e é usada como estratégia fisiológica frente à escassez de alimentos no período seco (SANTOS-CRUZ et al., 2009). O aporte de nutrientes afeta a percentagem de gordura omental (MUSHI et al., 2009).

Os pesos dos órgãos não constituintes da carcaça tenderam a um decréscimo conforme aumentaram os níveis de substituição, o que pode está relacionado à disponibilidade de energia das dietas, corroborando os resultados de Clementino et al. (2007). Órgãos e vísceras possuem distintas velocidades de crescimento durante a vida do animal, quando comparados a outras partes do corpo (KAMALZADEH et al., 1998), e podem ser influenciadas pela composição química da dieta, especialmente a energia.

Os coeficientes de correlação simples entre o peso vivo ao abate (PVA) e o fígado e PVA e gordura omental apresentaram as maiores magnitudes, comprovando a existência de forte associação entre estas variáveis $(\mathrm{P}<0,05)$ (Tabela 6). Assim, o aumento dos níveis de substituição do milho pelo subproduto da goiaba reduz o PVA, o peso do fígado $\mathrm{e}$ o percentual de gordura omental e gordura interna total (Tabelas 3 e 5). O resultado corrobora a afirmativa de Carvalho et al. (2005), onde os autores definem que $o$ confinamento proporciona um maior consumo diário de energia que, por sua vez, influencia as proporções de gordura interna nas carcaças. 
Rev. Bras. Saúde Prod. Anim., Salvador, v.17, n.1, p.101-115 jan./mar., 2016 http://www.rbspa.ufba.br

O PVA apresentou correlações positivas e significativas com os órgãos: língua $(\mathrm{r}=0,50)$, fígado $(\mathrm{r}=0,62)$, coração $(0,55)$, baço $(\mathrm{r}=0,59)$, sangue $(\mathrm{r}=0,36)$, rins $(\mathrm{r}=0,62)$, patas $(\mathrm{r}=0,54)$, pele $(\mathrm{r}=0,45)$, pulmão $(\mathrm{r}=0,57)$, TGI $(\mathrm{r}=0,61)$ e $\mathrm{GO}$ $(\mathrm{r}=0,64)$. Porém, não houve correlações significativas entre o PVA e os órgãos cabeça, testículos, gordura renal e gordura mesentérica. O PVA mostrou-se relevante como estimador de órgãos vitais como fígado, coração, baço, rins e pulmão, o que está relacionado à qualidade das dietas e a função biológica dos órgãos, onde menores níveis de substituição promoveram maiores taxas de crescimento e melhor desempenho dos animais.

Tabela 6. Correlações simples das medidas corporais in vivo com os órgãos não constituintes da carcaça de ovinos Santa Inês alimentados com diferentes níveis de substituição do milho pelo subproduto agroindustrial da goiaba na dieta

\begin{tabular}{lcccccc}
\hline Parâmetros $^{*}$ & PVA & COMP & AC & AG & LG & ESC \\
\hline Cabeça & - & - & 0,32 & - & - & - \\
Língua & 0,50 & - & 0,32 & - & - & - \\
Fígado & 0,62 & 0,44 & 0,41 & 0,37 & 0,35 & 0,44 \\
Coração & 0,55 & - & 0,45 & 0,45 & - & 0,41 \\
Baço & 0,59 & 0,32 & - & 0,42 & 0,43 & 0,33 \\
Sangue & 0,36 & 0,48 & - & - & 0,45 & - \\
Rins & 0,62 & 0,37 & 0,40 & 0,46 & 0,33 & 0,35 \\
Patas & 0,54 & 0,35 & 0,39 & 0,49 & - & - \\
Pele & 0,45 & 0,34 & 0,57 & 0,51 & - & 0,45 \\
Testículos & - & - & - & - & - & 0,34 \\
Pulmão & 0,57 & - & 0,37 & 0,45 & - & 0,32 \\
TGI & 0,61 & - & 0,49 & 0,50 & 0,32 & 0,35 \\
GR & - & - & - & - & - & 0,33 \\
GO & 0,64 & 0,31 & 0,40 & 0,41 & - & 0,53 \\
\hline
\end{tabular}

*Apenas as correlações significativas estão apresentadas $(\mathrm{P}<0,05)$. $\mathrm{PVA}=$ peso vivo ao abate; $\mathrm{COMP}=$ comprimento corporal; $\mathrm{AC}=$ altura de cernelha; $\mathrm{AG}=$ altura de garupa; $\mathrm{LG}=$ largura de garupa; $\mathrm{ESC}=$ escore corporal; $\mathrm{TGI}=$ trato gastrointestinal; $\mathrm{GR}=$ gordura renal; $\mathrm{GO}=$ gordura omental.

O comprimento corporal (COMP) apresentou correlação positiva com o peso do fígado $(\mathrm{r}=0,44)$; baço $(\mathrm{r}=0,32)$; sangue $(0,48)$, rins $(\mathrm{r}=0,37)$, patas $(\mathrm{r}=0,35)$, pele $(\mathrm{r}=0,34)$ e gordura omental $(\mathrm{r}=0,31)$. Porém, essas correlações apresentaram baixa intensidade o que repercute a necessidade de maiores informações cientificas. Segundo Berg \& Buterfield (1979), os órgãos vitais de animais adultos possuem baixo desenvolvimento, uma vez que já alcançaram seu tamanho máximo.
A altura de cernelha apresentou correlações significativas e positivas com a maioria dos órgãos estudados, exceto para o baço, sangue, testículos, gordura renal e gordura mesentérica. Já a altura de garupa, se correlacionou positivamente com o fígado $(\mathrm{r}=0,37)$; coração $(\mathrm{r}=0,45)$; baço $(\mathrm{r}=0,42) ;$ rins $(\mathrm{r}=0,46) ;$ patas $(\mathrm{r}=0,49)$; pele $(\mathrm{r}=0,51)$; pulmão $(\mathrm{r}=0,45)$; TGI $(r=0,50)$ e GO $(r=0,41)$. Com relação a largura de garupa, foi observado correlação significativa apenas com as características de fígado, baço, sangue, rins e TGI. Foi observado correlações 
Rev. Bras. Saúde Prod. Anim., Salvador, v.17, n.1, p.101-115 jan./mar., 2016 http://www.rbspa.ufba.br ISSN 15199940 http://dx.doi.org/10.1590/S1519-99402016000100010

entre a medida subjetiva de escore corporal e a maioria dos órgãos vitais dos animais. Portanto, confirma-se a hipótese de que o escore corporal é uma boa medida para predizer o rendimento dos componentes não constituintes da carcaça. Em estudos biométricos e de quantificação dos órgãos não constituintes da carcaça de ovinos, devese levar em consideração não só peso ao abate dos animais, mas, também, o tipo da dieta utilizada, em virtude do efeito dietético sobre a morfologia e fisiologia dos órgãos. Nesse sentido, evidenciou-se que os níveis de substituição do milho pelo subproduto da goiaba não favoreceu o rendimento dos órgãos não constituintes da carcaça, pois devido ao menor aporte energético das dietas com maiores percentagens do subproduto da goiaba, foi observado a influencia sobre as medidas biométricas e sobre $\mathrm{o}$ desempenho dos animais.

$\mathrm{Na}$ análise de regressão múltipla, utilizando as variáveis biométricas, entre as equações estatisticamente significativas, foram selecionadas aquelas que apresentaram maior precisão para estimar os dados observados (coeficiente de determinação) e com explicação e aplicação biológica.

Foi observado que o PVA deve aumentar $1,0980 \mathrm{~kg}$ para cada acréscimo de um ponto de ESC (Tabela 7). Em estudo realizado por Oregui et al. (1997) com ovelhas Latxa, descrevem que cada ponto de aumento na escala do escore corporal equivale a aproximadamente $5 \mathrm{~kg}$ ou $9,8 \%$ de peso corporal. Neste trabalho, o aumento de um ponto de escore promoveu aumento de $1,0980 \mathrm{~kg}$ de PVA, ou seja, valor inferior ao descrito pelo autor supracitado.

Tabela 7. Modelos lineares para predição do peso vivo ao abate (PVA), peso de carcaça quente (PCQ), peso de carcaça fria (PCF), índice de compacidade da carcaça (ICC), índice de compacidade da perna (ICP), rendimento de constituintes não-carcaça comestíveis (RCC) e conformação da carcaça (CC), com base na análise de regressão múltipla das medidas biométricas e morfométricas

\begin{tabular}{ll}
\hline Modelos lineares: & $\mathrm{R}^{2}$ \\
\hline PVA $=2,4531+1,0980 \mathrm{ESC}+0,0756 \mathrm{COMP}+(-0,0078 \mathrm{ALTA})+0,2022 \mathrm{ALTP}+0,0930 \mathrm{PT}+(-0,0586 \mathrm{LG})$ & 0,47 \\
PCQ $=-17,1851+1,2808 \mathrm{ESC}+0,0766 \mathrm{COMP}+0,0683 \mathrm{ALTA}+0,0819 \mathrm{ALTP}+0,1635 \mathrm{PT}+(-0,0054 \mathrm{LG})$ & 0,57 \\
PCF $=-17,2474+1,2412 \mathrm{ESC}+0,0773 \mathrm{COMP}+0,0737$ ALTA $+0,0728 \mathrm{ALTP}+0,1678 \mathrm{PT}+(-0,0048 \mathrm{LG})$ & 0,57 \\
ICC $=-0,1773+0,0034 \mathrm{COMPC}+(-0,0045 \mathrm{CIC})+0,0033 \mathrm{PCOX}+(-0,0003 \mathrm{LG})+0,0002 \mathrm{PFT}+0,0050 \mathrm{PT}+0,0001 \mathrm{PG}$ & 0,62 \\
ICP $=-0,2836+0,0061$ COMPC $+(-0,0002 \mathrm{CIC})+(-0,0101 \mathrm{PCOX})+0,0263 \mathrm{LG}+(-0,0076 \mathrm{PFT})+0,0066 \mathrm{PT}+0,0005 \mathrm{PG}$ & 0,66 \\
$\mathrm{RCC}=-0,6534+0,1889 \mathrm{COMPC}+0,0342 \mathrm{CIC}+0,1568 \mathrm{PCOX}+0,1987 \mathrm{LG}+(-0,1264 \mathrm{PFT})+0,2512 \mathrm{PT}+(-0,2756 \mathrm{PG})$ & 0,61 \\
$\mathrm{CC}=-1,3377+(-0,011 \mathrm{COMPC})+0,0114 \mathrm{CIC}+0,0194 \mathrm{PCOX}+0,0323 \mathrm{LG}+(-0,0013 \mathrm{PFT})+0,0606 \mathrm{PT}+(-0,0228 \mathrm{PG})$ & 0,43 \\
\hline
\end{tabular}

$\mathrm{ESC}=$ escore corporal; $\mathrm{COMP}=$ comprimento corporal; $\mathrm{ALTA}=$ altura do anterior ou de cernelha; $\mathrm{ALTP}=$ altura do posterior ou de garupa; $\mathrm{PT}=$ perímetro torácico. $\mathrm{COMPC}=$ comprimento de carcaça; $\mathrm{CIC}=$ comprimento interno de carcaça; $\mathrm{PCOX}=$ perímetro da coxa; $\mathrm{LG}=$ largura de garupa; $\mathrm{PFT}=$ profundidade do tórax; $\mathrm{PG}=$ perímetro de garupa.

Observou-se que o PCQ deve aumentar $1,2808 \mathrm{~kg}$ e $0,1635 \mathrm{~kg}$ para cada ponto de ESC e a cada $\mathrm{cm}$ de PT acrescido, respectivamente, inferindo que o PCQ é altamente dependente do ESC e PT. O
ESC e o PT são as variáveis biométricas que mais explicam a variação do PCF. Todavia, o PCF deve aumentar $1,2412 \mathrm{~kg}$ para cada acréscimo de um ponto de ESC e 0,1678kg para cada 
Rev. Bras. Saúde Prod. Anim., Salvador, v.17, n.1, p.101-115 jan./mar., 2016 http://www.rbspa.ufba.br ISSN 15199940

unidade de $\mathrm{cm}$ de PT. Todavia, as medidas obtidas a partir do animal vivo, como comprimento corporal, alturas do anterior e posterior, perímetro torácico e largura da garupa, associadas à avaliação subjetiva da condição corporal, constituem ferramentas importantes na determinação das características de peso vivo ao abate, peso de carcaça quente e peso de carcaça fria, podendo ser utilizadas para estimativa do momento ideal de abate. Pinheiro et al. (2007) afirmam que embora essas medidas não possam, isoladamente, definir as características da carcaça, permitem predizer algumas características produtivas importantes para o estudo do desempenho animal, corroborando os dados obtidos neste ensaio experimental.

Tendo como base as variáveis morfométricas, observou-se que o ICC deve aumentar $0,0034 \mathrm{~kg} / \mathrm{cm}$ a cada acréscimo de uma unidade de $\mathrm{cm}$ de comprimento de carcaça (COMPC), $0,0033 \mathrm{~kg} / \mathrm{cm}$ a cada unidade de $\mathrm{cm}$ de perímetro da coxa (PCOX) e $0,0050 \mathrm{~kg} / \mathrm{cm}$ a cada unidade acrescida de pts de perímetro torácico (PT). Por outro lado, o ICC deve diminuir $0,0045 \mathrm{~kg} / \mathrm{cm}$ a cada unidade acrescida de $\mathrm{cm}$ de comprimento interno de carcaça (CIC). Portanto, percebe-se uma relação positiva entre o ICC e as variáveis COMPC, PCOX e $\mathrm{PT}$, porém relação negativa ocorre entre o ICC e o CIC, o que já era esperado, uma vez que o índice de compacidade da carcaça mede a relação matemática entre o PCF e o CIC. É importante enfatizar que quanto maior o índice de compacidade corporal maior será a proporção de músculo e gordura nos animais, conforme relatado por Yáñez et al. (2004).

O índice de compacidade da perna deve aumentar 0,0061 e $0,0263 \mathrm{~kg} / \mathrm{cm}$ a cada unidade de $\mathrm{cm}$ de COMPC e LG, respectivamente. Porém, deve reduzir $0,0101 \mathrm{~kg} / \mathrm{cm}$ a cada unidade de $\mathrm{cm}$ de PCOX. Assim, quanto maior o comprimento da carcaça e a largura de garupa, maior será o ICP, por outro lado quanto maior o perímetro da coxa, menor o ICP. O rendimento de constituintes comestíveis (RCC) apresentou relação de dependência com as medidas de COMPC, LG, PT e PG, onde a cada unidade de $\mathrm{cm}$ acrescida no COMPC, LG, PT e PG, espera-se um aumento de 0,$1889 ; 0,1987$ e $0,2512 \%$, bem como redução de $-0,2756 \%$ no rendimento de constituintes não-carcaça comestíveis. Portanto, quanto maior o comprimento de carcaça (COMPC), largura de garupa (LG) e perímetro torácico $(\mathrm{PT})$, maior será o rendimento dos constituintes não-carcaça comestíveis em ovinos (RCC). Por fim, quanto maior o PT maior será a $\mathrm{CC}$, onde se espera um aumento de 0,0606 pts a cada cm de PT acrescido, o que é conseqüência da influencia da base óssea, muscular e depósitos de gordura sobre o perímetro torácico.

O subproduto agroindustrial da goiaba pode ser utilizado como substituto do milho em dietas para ovinos da raça Santa Inês em confinamento em níveis de até $164 \mathrm{~g} / \mathrm{kg}$ de MS, sem comprometer o rendimento dos principais órgãos não constituintes da carcaça como fígado, coração, baço, rins e pulmão. A partir das medidas obtidas in vivo e na carcaça é possível predizer com precisão, por meio de equações, os pesos e rendimentos de carcaça e constituintes não-carcaça de ovinos da raça Santa Inês. 
Rev. Bras. Saúde Prod. Anim., Salvador, v.17, n.1, p.101-115 jan./mar., 2016 http://www.rbspa.ufba.br ISSN 15199940

\section{REFERÊNCIAS}

ALMEIDA, T.R.V.; PEREZ, J.R.O.; CHLAD, M.; FRANÇA, P.M.; LEITE, R.F.; NOLLI, C.P. Desempenho e tamanho de vísceras de cordeiros Santa Inês após ganho compensatório.

Revista Brasileira de Zootecnia, v.40, n.3, p.616-621, 2011.

ALVES, K.S.; CARVALHO, F.F.R.; FERREIRA, M.A.; VÉRAS, A.S.C.; MEDEIROS, A.N.; NASCIMENTO, J.F.; NASCIMENTO, L.R.S.; ANJOS, A.V.A. Níveis de energia em dietas para ovinos Santa Inês: Características de carcaça e constituintes corporais.

Revista Brasileira de Zootecnia, v.32, n.6, p.1927-1936, 2003.

AZEVEDO, J.A.G.; VALADARES FILHO, S.C.; PINA, D.S.; DETMANN, E.; VALADARES, R.F.D.; PEREIRA, L.G.R.; SOUZA, N.K.P.; COSTA E SILVA, L.F. Consumo, digestibilidade total, produção de proteína microbiana e balanço de nitrogênio em dietas com subprodutos de frutas para ruminantes.

Revista Brasileira de Zootecnia, v.40, p.1052-1060, 2011.

BERG, R.T.; BUTTERFIELD, R.M. Nuevos conceptos sobre desarrollo de ganado vacuno. Zaragoza: Acribia, 1979. $297 \mathrm{p}$.

CAMILO, D.A.; PEREIRA, E.S.; PIMENTEL, P.G.; COSTA, M.R.G.F.; MIZUBUTI, I.Y.; RIBEIRO, E.L.A.; CAMPOS, A.C.N.; PINTO, A.P.; MORENO, G.M.B. Peso e rendimento dos componentes não-carcaça de ovinos Morada Nova alimentados com diferentes níveis de energia metabolizável. Semina: Ciências

Agrárias, v.33, n.6, p.2429-2440, 2012.
CARVALHO, S.; SILVA, M.F.;

CERUTTI, R.; KIELING, R.; OLIVEIRA, A.; DELEASTRE, $M$.

Desempenho e componentes do peso vivo de cordeiros submetidos a diferentes sistemas de alimentação. Ciência Rural, v.35, n.3, p.650-655, 2005.

CASTRO, F.A.B.; RIBEIRO, E.L.A.; KORITITIAKI, N.A.; MIZUBUTI, I.Y.; SILVA, L.D.F.; PEREIRA, E.S.; PINTO, A.P.; CONSTATINO, C.; FERNANDES JUNIOR, F.

Desempenho de cordeiros Santa Inês do nascimento ao desmame filhos de ovelhas alimentadas com diferentes níveis de energia. Semina: Ciências Agrárias, v.33, p.3379-3388, 2012.

CEZAR, M.F. SOUZA, W.H. Carcaças Ovinas e Caprinas: obtenção, avaliação e classificação. Uberaba, MG: Agropecuária Tropical, 2007. $147 \mathrm{p}$.

CLEMENTINO, R.H.; SOUSA, W.H.; MEDEIROS, A.N.; CUNHA, M.G.G.; GONZAGA NETO, S.; CARVALHO, F.F.R.; CAVALCANTE, M.A.B. Influencia dos níveis de concentrado sobre os cortes comerciais, os constituintes não-carcaça e os componentes da perna de cordeiros confinados. Revista Brasileira de Zootecnia, v.36, n.3, p.681-688, 2007.

COSTA JÚNIOR, G.S.; CAMPELO, J.E.G.; AZEVÊDO, D.M.M.R.; MARTINS FILHO, R.; CAVALCANTE, R.R.; LOPES, J.B.; OLIVEIRA, M.E. Caracterização morfométrica de ovinos da raça Santa Inês criados nas microrregiões de Teresina e Campo Maior, Piauí. Revista Brasileira de Zootecnia, v.35, n.6, p.2260-22676, 2006. 
Rev. Bras. Saúde Prod. Anim., Salvador, v.17, n.1, p.101-115 jan./mar., 2016 http://www.rbspa.ufba.br ISSN 15199940

KAMALZADEH, A.; VAN

BRUCHEM, J.; KOOPS, W,J.;

TAMMINGA, S.; ZWART, D. Feed

quality restriction and compensatory

growth in growing sheep: development

of body organs. Small Ruminant

Research, v.29, n.1, p.71-82, 1998.

LOUSADA JUNIOR, J.E.; COSTA, J.M.C.; NEIVA, J.N.M.; RODRIGUEZ,

N.M. Caracterização físico-química de subprodutos obtidos do processamento de frutas tropicais visando seu aproveitamento na alimentação animal.

Revista Ciência Agronômica, v.37, n.1, p.70-76, 2006.

LUCIANO, G.; MONAHAN, F.J.; VASTA, V.; BIONDI, L.; LANZA, M.; PRIOLO, A. Dietary tannins improve lamb meat colour stability. Meat Science, v.81, p.120-125, 2009.

MIN, B.R.; BARRY, T.N.; ATTWOOD, G.T.; MCNABB, W.C. The effect of condensed tannins on the nutrition and health of ruminants fed fresh temperate forages: a review.

Animal Feed Science and Technology, v.105, p.3-19, 2003.

BRASIL. Ministério da Agricultura.

Regulamento da Inspeção industrial e Sanitária de Produtos de Origem Animal. Brasília, DF: 1952. 154p.

MORENO, G.M.B.; SILVA

SOBRINHO, A.G.; LEÃO, A.G.; PEREZ, H.L.; LOUREIRO, C.M.B.; PEREIRA, G.T. Rendimento dos componentes não-carcaça de cordeiros alimentados com silagem de milho ou cana-de-açucar e dois níveis de concentrado. Revista Brasileira de Zootecnia, v.40, n.12, p.2878-2885, 2011.
MURTA, R.M.; CHAVES, M.A.; PIRES, A.J.V.; VELOSO, C.M.; SILVA, F.F.; ROCHA NETO, A.L.; EUSTÁQUIO FILHO, A.; SANTOS, P.E.F. Desempenho e digestibilidade aparente dos nutrientes em ovinos alimentados com dietas contendo bagaço de cana-de-açucar tratado com óxido de cálcio. Revista Brasileira de Zootecnia, v.40, p.1325-1332, 2011.

MUSHI, D.E.; SAFARI, J.; MTENGA, L.A.; KIFARO, G.C.; EIK, L.O.

Growth and distribution of non-carcass components of Small East African and F1 Norwegian crossbred goats under concentrate diets. Livestock Science, v.126, n.1, p.80-86, 2009.

NATIONAL RESEARCH COUNCIL NRC. Nutrient requeriments of small ruminants: Sheep, goats, cervids, and new world camelids. Washington:

National Academic Press, 2007. p.244265.

OREGUI, L.M.; VICENTE, M.S.; GARRO, J.; BRAVO, M.V. The relationship between body condition score and body weight in Latxa ewes. Animal Science, v.65, p.63-69, 1997.

PEREIRA, L.G.R.; BARREIROS, D.C.; OLIVEIRA, L.S.; FERREIRA, A.L.; MAURICIO, R.M.; AZEVEDO, J.A.G.; FIGUEIREDO, M.P.; SOUSA, L.F.; CRUZ, P.G. Composição química e cinética de fermentação ruminal de subprodutos de frutas no sul da BahiaBrasil. Livestock Research for Rural and Development, v.20, p.1-13, 2008.

PINHEIRO, R.S.B.; SILVA SOBRINHO, A.G.; MARQUES, C.A.T.; YAMAMOTO, S.M. Biometria in vivo e da carcaça de cordeiros confinados. Archivos de Zootecnia, v.56, n.216, p.955-958, 2007. 
Rev. Bras. Saúde Prod. Anim., Salvador, v.17, n.1, p.101-115 jan./mar., 2016 http://www.rbspa.ufba.br ISSN 15199940

PINHEIRO, R.S.B.; SILVA

SOBRINHO, A.S.; SIQUEIRA, G.R.;

ANDRADE, E.N. Amonização do resíduo da produção de sementes de forragem no desempenho e biometria de cordeiros. Ciência Animal Brasileira, v.10, n.3, p.711-720, 2009.

SANTANA, A. F.; COSTA, G.B.; FONSECA, L.S. Correlação entre peso e medidas corporais em ovinos Jovens da Raça Santa Inês. Revista Brasileira de Saúde e Produção Animal [online], v.1, p.74-77, 2001.

SANTOS, N.M.; COSTA, R.G.; MADRUGA, M.S.; MEDEIROS, A.N.M.; ALBUQUERQUE, C.L.C.; QUEIROGA, R.C.R.E. Constitution and Composition Chemistry of the Precooked Goatlike Buchada Produced in the State of Paraiba, Brazil.

Brazilian Archives of Biology and Technology, v.51, n.4, p.793-798, 2008.

SANTOS-CRUZ, C.L.; PÉREZ, J.R.O.; MUNIZ, J.A.; CRUZ, C.A.C.;

ALMEIDA, T.R.V. Desenvolvimento dos componentes do peso vivo de cordeiros Santa Inês e Bergamácia abatidos em diferentes pesos. Revista

Brasileira de Zootecnia, v.38, n.5, p.923-932, 2009.

SMITH, N.E.; BALDWIN, R.L. Effects of breed, pregnancy and lactation on weight of organs and tissues in dairy cattle. Journal Animal Science, v.57, n.4, p.1055-1061, 1973.

SOUSA, W.H.; BRITO, E.A.; MEDEIROS, A.N.; CARTAXO, F.T.; CEZAR, M.F.; CUNHA, M.G.G.

Características morfométricas e de carcaça de cabritos e cordeiros terminados em confinamento. Revista

Brasileira de Zootecnia, v.38, n.7, p.1340-1346, 2009.
VALADARES FILHO, S.C.; MAGALHÃES, K.A.; ROCHA JÚNIOR, V.R.R.; CAPELLE, E.R. Tabelas brasileiras de composição de alimentos para bovinos. 2 ed. Viçosa, MG: Universidade Federal de Viçosa, 2006. 329p.

YÁÑEZ, E.A.; RESENDE, K.T.; FERREIRA, A.C.D.; MEDEIROS, A.N.; SILVA SOBRINHO, A.G.; PEREIRA FILHO, J.M.; TEIXEIRA, I.A.M.A.; ARTONI, S.M.B. Utilização de medidas biométricas para predizer características da carcaça de cabritos Saanen. Revista Brasileira de Zootecnia, v.33, n.6, p.1564-1572, 2004.

Data de recebimento: 01/09/2014

Data de aprovação: 16/02/2016 